\title{
1 Trade-offs between chemical defence and regrowth capacity in
}

\section{Plantago lanceolata}

4 J. H. Reudler ${ }^{1,2}$, S. C. Honders ${ }^{1}$, H. Turin ${ }^{1}$ and A. Biere ${ }^{1}$

$7{ }^{1}$ Department of Terrestrial Ecology, Netherlands Institute of Ecology (NIOO-KNAW),

8 Droevendaalsesteeg 10, 6708 PB Wageningen, The Netherlands, current address: ${ }^{2}$ Centre of

9 Excellence in Biological Interactions Research, Department of Biological and Environmental

10 Science, University of Jyväskylä, Finland, email: jhtalsma@hotmail.com

12 Running title: Trade-offs between defence and regrowth

14 Keywords - fitness costs, iridoid glycosides, nutrient stress, Plantago lanceolata, regrowth

15 capacity, selection lines

17 Total word count: 5758

18 Abstract: 298

19 Introduction: 1153

20 Material and Methods: 1725

21 Results: 1049

22 Discussion: 1458

23 Acknowledgements: 75

25 Cited references: 77

26 Figures: 4

27 Supplementary Tables: 2

28 
29 Abstract - Resistance and tolerance are different strategies of plants to deal with herbivore

30 attack. Since resources are limited and resistance and tolerance serve similar functions for plants,

31 trade-offs between these two strategies have often been postulated. In this study we investigated

32 trade-offs between resistance and one aspect of tolerance, the ability to regrow after defoliation.

33 In order to minimize confounding effects of genetic background and selection history, we used

34 offspring derived from artificial selection lines of ribwort plantain (Plantago lanceolata) that

35 differed in their levels of leaf iridoid glycosides (IGs), allelochemicals that confer resistance to

36 generalist herbivores, to study genetic associations with regrowth ability. We tested whether

37 high-IG plants 1) suffer allocation costs of resistance in terms of reduced shoot and root growth,

38 2) have reduced regrowth ability (tolerance) after defoliation compared to low-IG plants, and 3)

39 whether such costs are more pronounced under nutrient stress. High-IG plants produced fewer

40 inflorescences and side rosettes than low-IG plants and showed a different biomass allocation

41 pattern, but since neither the vegetative, nor the reproductive biomass differed between the lines,

42 there was no evidence for a cost of IG production in terms of total biomass production under

43 either nutrient condition. High-IG plants also did not suffer a reduced capacity to regrow shoot

44 mass after defoliation. However, after regrowth, root mass of high-IG plants grown under

45 nutrient-poor conditions was significantly lower than that of low-IG plants. This suggests that

46 under these conditions shoot regrowth of high-IG plants comes at a larger expense of root growth

47 than in low-IG plants. We speculate therefore that if there is repeated defoliation, high-IG plants

48 may eventually fail to maintain shoot regrowth capacity and that trade-offs between resistance

49 and tolerance in this system will show up after repeated defoliation events under conditions of 50 low resource availability. 


\section{Introduction}

54 Two of the general defence strategies of plants against herbivores are resistance, reducing the

55 amount of herbivore damage, and tolerance, reducing the detrimental effects of herbivore damage

56 on plant fitness (Crawley 1983; Rosenthal and Kotanen 1994; Strauss and Agrawal 1999; Stowe

57 et al 2000). Resistance mechanisms include the production of secondary metabolites and

58 morphological structures that reduce herbivore preference or performance. Tolerance

59 mechanisms include increased photosynthetic activity, compensatory growth, utilization of stored

60 reserves, activation of dormant meristems and phenological and architectural traits that contribute

61 to maintaining high fitness in the face of damage (Tiffin 2000a). Tolerance may be an effective

62 strategy against specialist herbivores that are unaffected by chemical defences in the food plants

63 to which they have adapted (Crawley 1983; Giamoustaris and Mithen 1995; van der Meijden

64 1996).

65 Since both resistance and tolerance traits can incur fitness costs (e.g. Fineblum and 66 Rausher 1995; Stinchcombe 2002; Strauss et al 2002; Fornoni et al 2004a) and both defence

67 strategies are likely to draw upon the same pool of resources, trade-offs between these 68 mechanisms have often been postulated (van der Meijden et al 1988; Fineblum and Rausher 69 1995; Mauricio et al 1997; Leimu and Koricheva 2006), depending on relative costs and benefits 70 of these strategies (Tiffin 2000b; Fornoni et al 2004b; Restif and Koella 2004). Most plants seem

71 to exhibit a mixed pattern of defence, allocating resources to both types of defence strategies

72 (Núñez-Farfán et al 2007; Fornoni 2011) and meta-analyses of published studies on associations

73 between resistance and tolerance have not yielded strong support for general trade-offs between

74 these two defence strategies (Leimu and Koricheva 2006, see also Muola et al 2010; Tucker and

75 Avila-Sakar 2010, but see Oduor et al 2011), illustrating that conditions for negative associations 
76 between resistance and tolerance may be more restricted than previously thought (de Jong and 77 van der Meijden 2000).

One factor that may have strong impact on whether trade-offs between resistance

79 and tolerance occur is the strength of resource limitation (Agrawal 2011). In this paper we study

80 the impact of nutrient availability on the costs of chemical defence in terms of growth and

81 regrowth ability, one of the mechanisms underlying tolerance, within a species. Costs of defence

82 are expected to increase under stress conditions such as low light or nutrient stress and

83 competition for two reasons (Bergelson and Purrington 1996; Strauss et al 2002). First, trade-offs

84 between different functions such as growth and defence are more pronounced when resources are

85 more severely limiting (Herms and Mattson 1992). Second, environmental stress can cause

86 increased production of defence chemicals (Gershenzon 1984; Hirata et al 1993; Dixon and Paiva

87 1995), incurring larger costs. Thus far, reviews of studies addressing costs of defence in relation

88 to stress have not revealed a general pattern of more pronounced costs in stressful environments

89 (Bergelson and Purrington 1996; van Dam and Baldwin 2001). Two factors may be responsible

90 for this. First, increased production of secondary metabolites under severe resource limitation

91 may not always have a substantial extra cost. For instance, nutrient shortage may lead to a

92 relative excess of fixed carbon in the plant that can be transferred into carbon-based secondary

93 metabolites at virtually no extra cost (Herms and Mattson 1992). Secondly, competitive stress

94 may not result in enhanced costs of defence, if the production of these defences also provides a

95 benefit in competitive interactions (Siemens et al 2002).

96 In this study we investigate whether constitutive levels of two defence compounds in

97 Plantago lanceolata, the iridoid glycosides (IG) aucubin and catalpol, affect the plant's ability to

98 grow and regrow and whether such costs depend on nutrient conditions. Aucubin and catalpol are

99 carbon-based secondary metabolites in which $P$. lanceolata invests up to $9 \%$ of the dry weight 
100 (Bowers 1991). Variation in the constitutive foliar concentrations of IGs within and among

101 populations of $P$. lanceolata has a strong genetic component (Bowers and Stamp 1992, 1993;

102 Adler et al 1995; Marak et al 2000). The biosynthetic costs of these IGs are high (Gershenzon

103 1984), but previous studies of fitness costs of IGs in P. lanceolata in the absence of herbivores

104 and pathogens have produced mixed results. No costs of IGs could be detected in terms of

105 negative among-genotype correlations between the level of IGs and aboveground biomass of

106 plant growth (Adler et al 1995), but in another study costs were found in terms of lower

107 reproductive dry weight and a smaller number of inflorescences produced by plants selected for

108 high levels of leaf IGs (Marak et al 2003). None of these studies addressed effects of IG on the

109 ability to regrow after defoliation. Regrowth is one of the mechanisms underlying tolerance that

110 involves e.g. the use of resources stored in plant parts that are relatively free from herbivore

111 attack (van der Meijden et al 1988; Iwasa and Kubo 1997).

112 So far, studies addressing trade-offs between resistance and tolerance have been mainly

113 performed either as cross-species comparisons (e.g. Agrawal and Fishbein 2008), or by

114 comparing genotypes within a species (see e.g. Manzaneda et al 2010). As argued before (Strauss

115 et al 1999; Siemens et al 2002; Stowe and Marquis 2011), costs and trade-offs in such

116 comparisons are difficult to study, as they are confounded by differences in selection history and

117 variation in genetic background between individuals. Hence such studies are not able to address

118 whether trade-offs result from a process in which particular allele combinations involved have

119 been brought together by selection (but can easily be broken down again by recombination), or

120 whether such associations are due to pleiotropic effects that really pose a constraint. Artificial

121 selection studies offer the advantage that they can assess pleiotropic costs of resistance in terms

122 of tolerance, or vice versa, in the absence of confounding effects of linkage disequilibrium. To

123 our knowledge, this approach has only been used once before to study associations between 
124 chemical resistance and tolerance traits. Stowe (1998) showed that annual, rapidly cycling,

125 Brassica rapa selected for high foliar glucosinolate levels suffered reduced fruit and seed 126 production following partial defoliation compared to control and low-glucosinolate lines. It is

127 unknown how this trade-off is affected by resource availability or how selection for high levels of

128 chemical defence affects the regrowth ability, another aspect of tolerance, in longer lived species.

129 For this study we therefore used $P$. lanceolata plants that had been artificially selected for high

130 and low leaf IG concentrations (Marak et al 2000). We investigated whether plants selected for

131 high levels of IG (resistance trait) (1) suffer allocation costs in terms of reduced shoot and root

132 growth, (2) have reduced regrowth ability (tolerance), and (3) whether such costs are more

133 pronounced under nutrient stress. In addition we assessed whether defoliated plants were able to

134 attain similarly high levels of IGs in their regrown leaves as in non-defoliated plants (no cost of

135 regrowth in terms of resistance), and whether the ability to do so was as strong in plants from 136 high IG lines as in plants from low IG lines. 


\section{Materials and methods}

\section{Plants}

140 Plantago lanceolata L., ribwort plantain, is a rosette-forming, self-incompatible, wind-pollinated,

141 perennial herb that overwinters as a basal rosette and produces numerous leaves and spiked

142 inflorescences at the end of fibrous stalks in the spring and summer (Cavers et al 1980; Primack

143 and Antonovics 1982). It has a worldwide distribution and large ecological amplitude. Among the

144 secondary plant compounds produced by $P$. lanceolata are the two iridoid glycosides (IGs)

145 aucubin and catalpol (Duff et al 1965; Bowers and Stamp 1992; Adler et al 1995). Apart from

146 two caffeoyl phenylethanoid glucosides (Fons et al 1999), these two IGs are the main known

147 defence compounds of $P$. lanceolata (Suomi et al 2001). They are known to have a deterrent

148 effect on pathogens (Marak et al 2002), and generalist insect herbivores of $P$. lanceolata (Bowers

149 and Puttick 1988; Bowers 1991; Biere et al 2004). Previous feeding experiments have shown that

150 both IGs prolong the development time of the generalist lepidopteran species Spodoptera exigua

151 and Chrysodeixis chalcites and reduce their pupal and adult weight (Reudler et al 2011) and that

152 catalpol is the more toxic of the two IGs to generalist herbivores (Bowers and Puttick 1988).

153 However, both IGs also function as oviposition cues and feeding stimulants for specialist

154 herbivorous insects. For instance, aucubin is used as oviposition cue by Melitaea cinxia

155 (Nieminen et al 2003; Reudler Talsma et al 2008) whereas both IGs are used as oviposition cue

156 by Junonia coenia (Pereyra and Bowers 1988) and as feeding stimulants by a number of

157 specialist checkerspot butterflies (Bowers 1983). In some parts of its distribution P. lanceolata is

158 heavily defoliated by herbivores such as caterpillars of the specialist nymphalid butterfly

159 Melitaea cinxia, whose larvae feed gregariously in communal webs on the plant. 
161 Eight of these crosses were made between parents with low levels of leaf IGs ('low-IG crosses') 162 and eight between parents with high levels of leaf IGs ('high-IG crosses'). The parents originated

163 from two selection lines previously created after four generations of artificial selection for low 164 and high leaf IG concentrations ('low-IG line' and 'high-IG line') from a common base 165 population (Marak et al 2000). Previous studies have shown that average leaf IG levels differ ca.

166 four-fold between these lines, but that considerable variation is present among different plant

167 families within the lines as well (Marak et al 2000, 2003). On average, offspring from low-IG

168 crosses are thus expected to have lower leaf IG levels than offspring from high-IG crosses, but 169 considerable variation is expected within these sets of crosses as well, providing a range of IG 170 levels among crosses used in this study.

171

\section{Set up}

173 Sixty seeds from each of the 16 crosses were germinated on water agar in a growth cabinet (L:D

$17414: 10 \mathrm{~h} ; 25^{\circ} \mathrm{C} / 15^{\circ} \mathrm{C}$ ). After 14 days, seedlings were transplanted into plastic pots (diameter 13.0

$175 \mathrm{~cm}$, height $11.2 \mathrm{~cm}$ and volume $970 \mathrm{ml}$ ) with sand. All pots were placed on saucers so that 176 nutrient solution spilled from the bottom of the pot could be reabsorbed by the soil and plant.

177 The experiment consisted of three treatments: one clipping-and-regrowth treatment (R)

178 and two unmanipulated growth treatments, harvested at two different time points (U8 and U13).

179 In treatment $\mathrm{R}$, shoots were clipped just above the caudex and harvested 8 weeks after 180 transplantation $(\mathrm{T}=8)$. This harvest is referred to as " $\mathrm{R} 8$ ". Roots were then allowed to regrow new

181 shoots for another 5 weeks until roots and regrown shoots were harvested 13 weeks after 182 transplantation ( $\mathrm{T}=13)$, when plants started to senesce under low nutrient conditions ("R13”). 183 One set of unmanipulated plants was harvested at the time of clipping ("U8"), the other 
184 simultaneously with the final harvest thirteen weeks after transplantation ("U13"). Each treatment

185 was performed under two nutrient conditions. Nutrient treatments ('rich' and 'poor') were 186 performed by adding different strengths of nutrient solution to the pots. The first two weeks all

187 the plants received the same amount of nutrients (50ml of a $1 / 32$ strength Hoagland solution) to

188 facilitate good establishment. Nutrient treatments were started two weeks after transplantation.

189 Half of the pots of each growth treatment (R, U8, U13) received a low nutrient level: $50 \mathrm{ml}$ of a

$1901 / 32$ strength Hoagland's solution from $\mathrm{T}=2$ to $\mathrm{T}=4$ and a 1/16 strength Hoagland's solution from

$191 \mathrm{~T}=4$ to $\mathrm{T}=13$ (poor). The other half of the pots received a high nutrient level: $50 \mathrm{ml}$ of a 1/8

192 strength Hoagland's solution from $\mathrm{T}=2$ to $\mathrm{T}=13$ (rich). Full strength Hoagland's solution

193 contained: $5 \mathrm{mM} \mathrm{Ca}\left(\mathrm{NO}_{3}\right)_{2}, 5 \mathrm{mM} \mathrm{KNO}_{3}, 1 \mathrm{mM} \mathrm{KH}_{2} \mathrm{PO}_{4}, 2 \mathrm{mM} \quad \mathrm{MgSO}_{4}, 174 \mu \mathrm{M}$

$194 \mathrm{C}_{10} \mathrm{H}_{12} \mathrm{FeN}_{2} \mathrm{O}_{8} \mathrm{Na}, 93 \mu \mathrm{M} \mathrm{H}_{3} \mathrm{BO}_{3}, 18 \mu \mathrm{M} \mathrm{MnCl}_{2}, 1.5 \mu \mathrm{M} \mathrm{ZnSO}_{4}, 0.6 \mu \mathrm{M} \mathrm{CuSO}_{4}$ and $1.0 \mu \mathrm{M}$

$195 \mathrm{Na}_{2} \mathrm{MoO}_{4}$.

196 All plants were watered individually 3 times a week. During the last five weeks (after the

197 first harvest of treatment R), pots of treatment U13 (not clipped) received 100ml solution to meet

198 their increased water demands without lowering soil nutrient concentration. In total the

199 experiment consisted of 16 genotypes x 3 treatments x 2 nutrient levels x 6 replicates, 576 plants,

200 that were grown in a randomized block design with three blocks, each containing two of the six

201 replicates per treatment combination, located on different benches within the same greenhouse

202 compartment. Plants within blocks were rotated every week and rearranged after harvest of the 203 U8 plants.

\section{Measurements}

206 At $\mathrm{T}=8$, 8 weeks after transplantation, the shoots of all the plants in treatment R8 and the 207 complete plants of treatment U8 were harvested. At $\mathrm{T}=13,13$ weeks after transplantation, 
208 complete plants of treatment R13 and U13 were harvested. For all plants we measured the day 209 that they produced their first inflorescence, and at harvest we measured the number of rosettes, 210 number of leaves and the length and width of their longest leaf. After harvest, roots were rinsed

211 clean and plants were separated into roots, vegetative shoots and reproductive parts. All fractions

212 per plant were put at $-80^{\circ} \mathrm{C}$ before freeze-drying. After freeze-drying, the plant parts were

213 weighed to determine their dry mass.

214 At $\mathrm{T}=8$, we had two sets of plants from which aboveground tissues were harvested, R8

215 plants and U8 plants. Plants from U8 were used for analyses of biomass and size-related traits,

216 since from these plants also roots were harvested. Plants from R8 were used for leaf chemical

217 analyses, since this allowed comparison of leaf IG concentrations from the same plants before 218 and after defoliation. Sample sizes for leaf chemical analyses differed among treatments. Leaf 219 samples from all plants (six replicates per treatment combination) of R8 (clipped leaves) and U13

220 plants were used for leaf chemical analyses. For plants of treatment R13 (regrown leaves) part of 221 the samples were lost and only three replicates per treatment combination were used for leaf 222 chemical analyses.

Since plants from the $\mathrm{R}$ treatment were left to regrow new leaves after defoliation, we 224 lack measurements of individual root weights of these plants at $\mathrm{T}=8$. As we wanted to relate the 225 regrowth ability of plants from different crosses in treatment $\mathrm{R}$ to both their IG levels and their 226 root dry weight at the time of defoliation, we estimated dry weights of roots in treatment $\mathrm{R}$ at $227 \mathrm{~T}=8$ as follows. First, we fitted general linear models to estimate how well ln-root dry weight of 228 plants in treatment U8 (harvested at the same time as defoliation of R plants took place) could be 229 predicted from their ln-shoot dry weight and the cross from which they originated. Both ln-shoot 230 dry weight and cross significantly affected ln-root dry weight under nutrient-poor conditions $\left(\mathrm{F}_{1}\right.$, $2316_{62}=358.8, \mathrm{P}<0.001$ and $\mathrm{F}_{15,62}=4.76, \mathrm{P}<0.001$, respectively, interaction n.s.) and under nutrient- 
232 rich conditions $\left(\mathrm{F}_{1,59}=89.23, \mathrm{P}<0.001\right.$ and $\mathrm{F}_{15,59}=3.91, \mathrm{P}<0.001$, respectively, interaction n.s.),

233 explaining $84 \%$ and $68 \%$ of variation in ln-root dry weight under nutrient-poor and rich

234 conditions, respectively. Then, the parameter estimates from these analyses were used to estimate

235 In-root dry weight of plants in treatment R from their ln-shoot dry weight in treatment R and the 236 cross from which they originated.

\section{Chemical analyses}

239 Samples of the freeze-dried leaves were ground to a fine powder with a ball mill (type MM 301,

240 Retsch GmbH \& Co., Haan, Germany). Ground leaf material (25mg) was extracted in $10 \mathrm{ml}$ of

$24170 \% \mathrm{MeOH}$ and was shaken overnight $\left(15^{\circ} \mathrm{C}, 100 \mathrm{RPM}\right)$. The crude extract was filtered using

242 Whatman filter paper \#4 and the filtrate was diluted ten times with Milli-Q water. The

243 concentrations of the IG aucubin and catalpol were analysed by HPLC using a Bio-Lc (Dionex

244 Corp., Sunnyvale, USA) equipped with a GP40 gradient pump, a Carbopac PA 1 guard (4 x 50

$245 \mathrm{~mm})$ and analytical column $(4 \times 250 \mathrm{~mm})$, and an ED40 electrochemical detector for pulsed

246 amperimetric detection (PAD). $\mathrm{NaOH}(1 \mathrm{M})$ and Milli-Q water were used as eluents (10:90,

$2471 \mathrm{ml} / \mathrm{min}$ ). Retention times were $3.25 \mathrm{~min}$ and $4.40 \mathrm{~min}$ for aucubin and catalpol, respectively.

248 Peaks were analyzed using Chromeleon version 6.60 (Dionex Corp., Sunneyvale, USA). Leaf

249 concentrations of aucubin and catalpol were expressed as a percentage of total leaf dry weight. In

250 addition to aucubin and catalpol, we also analysed the concentration of total IGs (i.e., the sum of

251 aucubin and catalpol) and the ratio of catalpol to the total IGs. Since catalpol is the more toxic of

252 the two components towards generalist insects (Bowers and Puttick 1988; Bowers 1991, 1992),

253 this ratio is likely to reflect an important aspect of direct defense in addition to the total 254 concentration of IGs. 


\section{Statistical analyses}

257 The effects of Block, Line (selection line from which parents of the crosses originated), Cross

258 (nested within Line), Nutrient level and their interaction effects on the different plant traits were 259 analyzed using GLM (Generalized Linear Models) (SAS v. 9.2, procedure GENMOD, SAS 260 Institute, Cary, NC) with a normal error distribution and an identity link function. Dependent 261 variables were transformed prior to analysis if necessary to improve normality. The number of

262 leaves and all weight measurements were $\ln$-transformed and the IG levels were square root263 transformed. In addition, we used (Pearson) correlations to analyse associations between (cross 264 means for) leaf IG levels and (cross means for) growth, reproduction, or regrowth capacity. 265 Allocation costs of chemical defence in terms of growth, reproduction, or regrowth would show 266 up either as Line effects for these traits in GLM (lower performance by plants of the high-IG 267 crosses), or as negative correlations between cross-means for these traits and cross-means for leaf 268 IG levels. 


\section{Results}

\section{Differences in leaf IG between crosses}

272 Leaf IG concentrations at $\mathrm{T}=8$ were approximately two-fold higher in crosses from the high-IG

273 line than in crosses from the low-IG line, under both nutrient conditions (Table S1; Fig. 1a). Both

274 aucubin (Fig. 1b) and catalpol (Fig. 1c) contributed to this difference (Table S1). Leaf IG

275 concentrations at $\mathrm{T}=8$ also varied significantly among crosses within lines, resulting in a three- to

276 four-fold range of variation in mean leaf IG concentrations among offspring groups from the 16

277 different crosses. Interestingly, the ratio of catalpol-to-total IG, which did not differ significantly

278 between lines (Table S1, Fig. 1d) did show large variation among the crosses within these lines

279 (Table S1). Leaf IG concentrations were on average 1.7 fold higher under nutrient-poor 280 conditions than under nutrient-rich conditions (Table S1, Fig. 1a). This difference could be 281 mainly attributed to higher leaf concentrations of aucubin under these conditions. The relative 282 difference in IG concentration between crosses from the high and low line was not significantly 283 affected by nutrient supply (no interaction line x nutrient, Table S1).

284 At $\mathrm{T}=13$, unmanipulated plants from the high-IG line still had significantly higher leaf IG 285 concentrations than plants from the low-IG line (Table S1, Fig. 1a). Leaf IG concentrations 286 showed a clear ontogenetic pattern. Under nutrient-poor conditions, plants from both lines had 287 higher leaf concentrations of aucubin at $\mathrm{T}=13$ than at $\mathrm{T}=8$ (Fig. 1b), whereas concentrations of 288 catalpol were similar between time points (Fig. 1c), resulting in a decline in the ratio of catalpol289 to-total IG (Fig. 1d) over time. Under nutrient-rich conditions, only plants from the high line 290 appeared to have higher leaf aucubin concentrations at $\mathrm{T}=13$ than at $\mathrm{T}=8$, whereas plants from the

291 low line had lower leaf catalpol concentrations than at $\mathrm{T}=8$, also resulting in a decline in the ratio 292 of catalpol-to-total IG over time (Fig. 1d). 


\section{Growth costs of iridoid glycosides}

294 Total dry weight of plants varied significantly among crosses, both at $\mathrm{T}=8$ and $\mathrm{T}=13$ (Table S2),

295 but plants from crosses from the high-IG line did not have a lower total dry weight than plants

296 from crosses from the low-IG line (Table S2; Fig. 2a), indicating that there was no general

297 growth cost of producing high levels of leaf IG under the conditions of the experiment. This is

298 confirmed by the absence of negative correlations between cross means for leaf IG and total dry

299 weight at $\mathrm{T}=8$ (nutrient-poor: $\mathrm{r}=-0.31, \mathrm{n}=16, \mathrm{P}=0.24$; nutrient-rich: $\mathrm{r}=-0.13, \mathrm{n}=16, \mathrm{P}>0.5$ ) or

$300 \mathrm{~T}=13$ (nutrient-poor: $\mathrm{r}=-0.17, \mathrm{n}=16, \mathrm{P}>0.5$; nutrient-rich $\mathrm{r}=0.34, \mathrm{n}=16, \mathrm{P}=0.20$ ). However,

301 biomass allocation patterns and plant architecture differed between plants from the high-IG and

302 low-IG line. First, plants from the high-IG line invested a smaller fraction of their biomass into

303 roots: at $\mathrm{T}=8$ their root mass fraction (root/total biomass) was significantly lower than that of

304 plants from the low-IG line (Table S2; Fig. 2b), although the difference in absolute biomass of

305 roots between the lines was not significant (Table S2; Fig. 2c). Second, at $\mathrm{T}=13$, when plants

306 under nutrient-rich conditions had invested on average more than $30 \%$ of their aboveground dry

307 weight in reproduction, plants from the high line had produced fewer inflorescences than plants

308 from the low line (Table S2; Fig. 2d). This could indicate a potential reproductive cost of high

309 leaf IG production, however the reduced number of inflorescences was not accompanied by a

310 significantly lower reproductive biomass (Table S2; Fig. 2e). Plants under nutrient rich

311 conditions developed their first inflorescence significantly earlier than plants under nutrient poor

312 conditions, for both selection lines (nutrient effect, $\mathrm{F}[1,163]=176.8, \mathrm{P}<0.001$ ). Third, shoot

313 architecture differed between plants from the high-IG and low-IG line. Plants from the high line

314 produced significantly fewer side rosettes and leaves per plant (Table S2; Fig. 2f,g) but the leaf

315 area (length $\mathrm{x}$ width) of their longest leaf was significantly larger than that of plants from the low

316 line (Table S2; Fig. 2h). 


\section{Regrowth costs of iridoid glycosides}

319 Plants defoliated at $\mathrm{T}=8$ were not able to achieve full growth compensation by $\mathrm{T}=13$, i.e. they had

320 lower biomass at $\mathrm{T}=13$ than plants that had been allowed to grow undisturbed until $\mathrm{T}=13$ (Fig.

321 2a). On average, the biomass of regrown shoots on plants defoliated at $\mathrm{T}=8$ was $27 \%$ and $51 \%$

322 lower than the shoot biomass of unclipped control plants at $\mathrm{T}=13$ under nutrient-poor and

323 nutrient-rich conditions, respectively (Fig. 2i). Shoot biomass at $\mathrm{T}=13$ produced by plants that

324 had been defoliated at $\mathrm{T}=8$ (regrowth) was positively correlated with their estimated root biomass

325 at the time of defoliation (Fig. 3), but did not differ between plants from crosses originating from

326 the high-IG and the low-IG line (Table S2; Fig. 2i), indicating that there is no trade-off between

327 production of direct defence chemicals and the regrowth of shoot biomass. However, plants from

328 the high-IG line did produce significantly fewer inflorescences after defoliation than plants from

329 the low-IG line (Table S2, Fig. 2d), as was observed for untreated plants at T=13. Moreover, at

330 low nutrient supply, the root biomass of high-IG plants, that already tended to be lower than that

331 of low-IG plants at the time of their defoliation (low nutrient supply, line effect: $F[1,14]=3.48, \mathrm{P}$

$332=0.08$; Fig. $2 \mathrm{c})$, was now significantly lower than that of low-IG plants $(\mathrm{F}[1,14]=8.19, \mathrm{P}=$

333 0.013; Fig. 2c). Accordingly, there was a significantly negative correlation between the mean IG

334 concentration of the different crosses at $\mathrm{T}=8$ and their mean root biomass five weeks after

335 defoliation at $\mathrm{T}=13$, under nutrient-poor conditions (Fig. 4; $\mathrm{r}=-0.55, \mathrm{n}=16, \mathrm{P}=0.03$ ). At high

336 nutrient supply, the difference in root weight between plants from low- and high-IG lines was not

337 significant.

338

339 IG of regrown leaves following defoliation 
340 IG concentrations of regrown, new, leaves of plants at $\mathrm{T}=13$ whose leaves had been defoliated at

$341 \mathrm{~T}=8$ (Fig. 1, R) differed from those of unmanipulated plants at $\mathrm{T}=13$. Under nutrient-poor

342 conditions, regrown leaves contained similar concentrations of aucubin (Fig. 1b), but

343 significantly lower levels of catalpol (Fig. 1c), resulting in lower catalpol-to-total ratios compared

344 to unmanipulated plants at $\mathrm{T}=13$ (Fig. 1d). This could indicate that there is a trade-off between

345 regrowth and the production of catalpol under nutrient-poor conditions. By contrast, under

346 nutrient-rich conditions, regrown leaves of plants from the low line contained higher IG (both

347 aucubin and catalpol) concentrations than leaves from unmanipulated plants, without affecting

348 the catalpol-to-total ratio.

349 


\section{Discussion}

\section{Regrowth costs of IGs}

352 Several studies have reported costs of chemical defence in terms of tolerance to herbivory. For

353 instance, high glucosinolate levels were associated with reduced tolerance of damage by

354 caterpillars of Pieris rapae in wild radish (Strauss et al 2003) and with reduced tolerance to

355 partial defoliation in Brassica rapa (Stowe 1998), costs of nicotine were observed in terms of

356 tolerance of damage by nematodes (Preisser et al 2007), and proteinase inhibitors incurred a cost

357 in terms of regrowth in Nicotiana attenuata (Zavala and Baldwin 2006). Regrowth capacity

358 depends in part on energy and nutrients that are saved and stored in organs that are relatively free

359 from attack. These reserves can be reallocated after herbivory. Plants from high-IG crosses had

360 lower root mass fractions than plants from the low-IG crosses, but their absolute root biomass

361 was not significantly lower than that of low-IG crosses and consequently they did not have a

362 lower regrowth capacity after defoliation. This indicates that there was no cost of high IG

363 production in terms of reduced shoot regrowth after defoliation under the competition-free

364 conditions of our experiment. However, especially under nutrient-poor conditions, plants that had

365 high levels of leaf IG at the time of defoliation had significantly lower root biomass at the final

366 harvest $(\mathrm{T}=13)$. This likely indicates that under nutrient-poor conditions, plants from high-IG

367 crosses are well able to regrow new shoots, but do so at a slightly larger expense of new root

368 growth than plants from low-IG crosses. After a single defoliation event we would therefore not

369 see a negative effect of high IG production on shoot regrowth. But as shoot regrowth is strongly

370 and positively correlated with root mass at the time of defoliation (Fig. 3), we expect that after

371 repeated defoliation the progressively stronger reduction of root mass of high-IG plants will

372 eventually result in a reduced capacity of shoot regrowth compared to low-IG plants, i.e. will 
373 eventually result in a cost of resistance in terms of regrowth capacity under nutrient-poor

374 conditions. This conclusion should be viewed with caution since our study is based on

375 experimental defoliation using scissors. Contact with oral secretions of herbivorous insects can

376 profoundly alter a plant's response to defoliation. For instance, down-regulation of systemin after

377 contact with oral secretion of Manduca sexta caterpillars results in increased root allocation in

378 Solanum nigrum (Schmidt and Baldwin 2009), which may actually prevent depletion of stored

379 reserves by shoot regrowth following defoliation.

381 Chemical defence of regrown leaves

382 Numerous studies have shown that the defence chemistry of leaves that have regrown on plants 383 following partial or complete defoliation can considerably differ from the defence chemistry of 384 corresponding leaves on undamaged plants (e.g. Katjiua and Ward 2006; Rooke and Bergstrom 2007; Verges et al 2008; Roitto et al 2009). Together with concomitant changes in primary 386 metabolites, such differences in leaf chemistry may have large effects on the palatability of the 387 newly formed leaves. Barton (2008) observed that 4-week old P. lanceolata plants that suffered $38850 \%$ defoliation by caterpillars of the specialist lepidopteran Junonia coenia showed a transient, $38980 \%$, decrease in IG concentrations one week after damage, but that IG concentrations had 390 increased to levels not different from control plants five weeks later. Our results largely confirm

391 the absence of differences in total IG concentrations between regrown and control leaves 5 weeks 392 after damage, under nutrient-rich conditions. Under these conditions, IG concentrations in leaves

393 that had regrown on plants from low-IG crosses were even slightly higher than those of control 394 plants at similar plant age. However, under nutrient-poor conditions, the relative amounts of 395 aucubin and catalpol were strongly affected by defoliation. Regrown leaves on plants that had 396 been defoliated at $\mathrm{T}=8$ had both a significantly lower amount of catalpol and a significantly lower 
ratio of catalpol to total $\mathrm{IG}$ at $\mathrm{T}=13$ than control plants at $\mathrm{T}=13$. The latter result is consistent

398 with a previous study showing a reduced catalpol to total IG ratio in $P$. lanceolata five weeks

399 after defoliation (Stamp and Bowers 1994). Aucubin and catalpol differ in their biological

400 activity (Bowers 1991; Marak et al 2002). Catalpol is considered the more toxic of the two for

401 generalist herbivores (Bowers and Puttick 1988; Bowers 1991, 1992). Consequently, the relative

402 contribution of aucubin and catalpol to the total IG pool is biologically relevant. After

403 defoliation, regrown shoots may therefore be more susceptible to generalist herbivores than

404 shoots of plants that were not defoliated.

405

406 Growth and reproduction costs of IGs

407 In addition to the, at least initial, absence of regrowth costs of chemical defense, we also did not

408 observe strong growth (biomass production) costs of chemical defense under the conditions of the

409 experiment. A fundamental assumption of most plant defence theories is that limited resources

410 lead to allocation constraints, often depicted as trade-offs between the production of secondary

411 plant compounds and other fitness-enhancing traits. In the absence of natural enemies the

412 production of these defence chemicals will then have fitness costs. In our study we did not find

413 evidence for a trade-off between chemical defence and biomass production at either nutrient

414 level. Plants from the high-IG line had fewer but larger leaves than plants from the low-IG line,

415 resulting in similar leaf and shoot biomass. Plants from the high-IG line invested a smaller

416 fraction of their total biomass in roots, which might suggest a potential cost of chemical defence

417 in environments where low investment in roots is disadvantageous. However, for undamaged

418 plants, differences in the absolute amount of root mass between plants from high- and low-IG

419 lines were not significant, partly because of the large variation in root biomass between crosses

420 within each of the lines. The large variation in root mass among crosses within the high- and low- 
421 IG lines may also explain why previous studies that used just one cross from each line found

422 either no difference (de Deyn et al 2009) or even higher (Wurst et al 2008) root mass in plants 423 from a high-IG cross compared to plants from a low-IG cross.

424 A consistent potential fitness cost of IG production that we observed was the smaller 425 number of inflorescences and side rosettes produced by plants from high-IG crosses compared to 426 plants from low-IG crosses under nutrient-rich conditions. This finding is consistent with other 427 studies reporting reproductive costs of chemical defence (e.g. Berenbaum et al 1986; Zangerl and 428 Berenbaum 1997, Stowe and Marquis 2011) and confirms results from a previous study in $P$. 429 lanceolata based on the same selection lines (Marak et al 2003; Wurst et al 2008). However, 430 since the reduction in inflorescence number was not accompanied by a lower reproductive 431 biomass, further studies are necessary to investigate whether the expected reduction in the 432 number of seeds produced is partly compensated by a higher individual seed mass and the fitness 433 consequences of these differences under different environmental conditions.

434 Increased costs of chemical defence under conditions with environmental stress are 435 expected, based on the arguments that a given investment in defence more strongly constrains 436 other fitness-enhancing traits at low than at high resource levels. However, the precise effects 437 will depend on the type of stress and the type of chemicals involved (Agrawal 2011). IGs are 438 carbon-based secondary metabolites. According to the carbon-nutrient balance hypothesis 439 (Bryant et al 1983; Bryant et al 1988; Tuomi et al 1988), plants in resource-limited environments 440 could divert the carbon reserves that they accumulate beyond growth requirements to secondary 441 metabolism without a trade-off in growth (Bryant et al 1985). Indeed, we observed higher levels 442 of IGs under nutrient poor conditions, as previously shown in P. lanceolata (Darrow and Bowers 443 1999; Marak et al 2003), without observing stronger reductions in growth or reproduction, than 444 under nutrient-rich conditions. This confirms results from Marak et al (2003) who did not find 
445 evidence for enhanced costs of chemical defence in this system under low nutrient conditions.

446 Some studies have reported that costs of carbon-based chemical defence can even be higher

447 under nutrient-rich conditions (Stevens et al 2007) where the resistance chemicals directly

448 compete with growth for limited carbon resources. It is therefore likely that stress-enhanced costs

449 of carbon based defences such as IGs are more readily observed under light than under nutrient

450 stress.

451

452 In summary, we detected allocation costs of chemical defence in terms of reduced numbers of 453 side rosettes and inflorescences by high-IG plants. After a single defoliation event, we did not 454 observe a trade-off between resistance and tolerance, i.e., plants with high levels of a trait that 455 confers resistance to generalist insects (IG level) did not have lower tolerance (shoot regrowth 456 capacity) than plants with lower IG levels. However, since high IG plants did suffer reduced root 457 biomass after a single defoliation and since root mass strongly determines shoot regrowth 458 capacity, we expect that trade-offs between resistance and tolerance will become apparent after 459 repeated defoliation.

\section{Acknowledgements}

462 We thank E. van der Meijden for his constructive comments on an earlier version of the

463 manuscript. L. Reudler Talsma and R. M. Niermeyer are acknowledged for their help with 464 weighing and grinding of the samples and Francesca Rinaldi for her help with the HPLC465 analyses. This study was supported by a grant from the Earth and Life Science Foundation 466 (ALW) of the Netherlands Organization for Scientific Research (NWO). Publication 5342 467 Netherlands Institute of Ecology (NIOO-KNAW). 


\section{References}

470 Adler LS, Schmitt J, Bowers MD (1995) Genetic-variation in defensive chemistry in Plantago 471 lanceolata (Plantaginaceae) and its effect on the specialist herbivore Junonia coenia (Nymphalidae). Oecologia 101:75-85

Agrawal AA (2011) Current trends in the evolutionary ecology of plant defence. Funct Ecol $25: 420-432$

Agrawal AA, Fishbein M (2008) Phylogenetic escalation and decline of plant defense strategies. Proc Natl Acad Sci USA 105:10057-10060

Barton KE (2008) Phenotypic plasticity in seedling defense strategies: compensatory growth and chemical induction. Oikos 117:917-925

Berenbaum MR, Zangerl AR, Nitao JK (1986) Constraints on chemical coevolution: wild parsnip and the wild parsnip webworm. Evolution 40:1215-1228

Bergelson J, Purrington CB (1996) Surveying patterns in the cost of resistance in plants. Am Nat $148: 536-558$

Biere A, Marak HB, van Damme JMM (2004) Plant chemical defense against herbivores and pathogens: generalized defense or trade-offs? Oecologia 140:430-441

Bowers MD (1983) The role of iridoid glycosides in host-plant specificity of checkerspot butterflies. J Chem Ecol 9:475-793

Bowers MD (1991) Iridoid glycosides. In: Rosenthal GA, Berenbaum MR (eds) Herbivores: their interactions with secondary plant metabolites. Academic Press, San Diego, pp 297-325

Bowers MD (1992) Evolution of unpalatability and the cost of chemical defense in insects. In: Roitberg BD, Isman MB (eds) Insect chemical ecology: an evolutionary approach. Chapman and Hall, New York, pp 216-244 
492 Bowers MD, Puttick GM (1988) Response of generalist and specialist insects to qualitative $493 \quad$ allelochemical variation. J Chem Ecol 14:319-334

494 Bowers MD, Stamp NE (1992) Chemical variation within and between individuals of Plantago lanceolata (Plantaginaceae). J Chem Ecol 18:985-995

496 Bowers MD, Stamp NE (1993) Effects of plant-age, genotype, and herbivory on Plantago performance and chemistry. Ecology 74:1778-1791

498 Bryant JP, Chapin FS, Klein DR (1983) Carbon/nutrient balance of boreal plants in relation to 499 vertebrate herbivory. Oikos 40:357-368

500 Bryant JP, Chapin FS, Reichardt P, et al (1985) Adaptation to resource availability as a 501 determinant of chemical defense strategies in woody plants. Recent Adv Phytochem $19: 219-237$

503 Bryant JP, Tuomi J, Niemelä P (1988) Environmental constraint of constitutive and long-term 504 inducible defenses in woody plants. In: Spencer KC (ed) Chemical medation of 505 coevolution. Academic Press, San Diego, pp 367-389

506 Cavers PB, Bassett IJ, Crompton CW (1980) The biology of Canadian weeds. 47. Plantago 507 lanceolata L. Can J Plant Sci 60:1269-1282

508 Crawley MJ (1983) Herbivory. Blackwell, Oxford.

509 Darrow K, Bowers MD (1999) Effects of herbivore damage and nutrient level on induction of $510 \quad$ iridoid glycosides in Plantago lanceolata. J Chem Ecol 25:1427-1440

511 de Deyn GB, Biere A, van der Putten WH, et al (2009) Chemical defense, mycorrhizal 512 colonization and growth responses in Plantago lanceolata L. Oecologia 160:433-442

513 de Jong G, van der Meijden E (2000) On the correlation between allocation to defence and $514 \quad$ regrowth in plants. Oikos 88:503-508 
515 Dixon RA, Paiva NL (1995) Stress-induced phenylpropanoid metabolism. Plant Cell 7:1085-

$516 \quad 1097$

517 Duff RB, Bacon JSD, Mundie CM, et al (1965) Catalpol and methylcatalpol: naturally ocurring 518 glycosides in Plantago and Buddleia species. Biochem J 96:1-5

519 Fineblum WL, Rausher MD (1995) Tradeoff between resistance and tolerance to herbivore 520 damage in a morning glory. Nature 377:517-520

521 Fons F, Tousch D, Rapior S, et al (1999) Phenolic profiles of untransformed and hairy root 522 cultures of Plantago lanceolata. Plant Physiol Biochem 37:291-296

523 Fornoni J (2011) Ecological and evolutionary implications of plant tolerance to herbivory. Funct 524 Ecol 25:399-407

525 Fornoni J, Valverde PL, Núñez-Farfán J (2004a) Population variation in the cost and benefit of

$526 \quad$ tolerance and resistance against herbivory in Datura stramonium. Evolution 58:1696527 1704

528 Fornoni J, Núñez-Farfán J, Valverde PL, et al (2004b) Evolution of mixed strategies of plant 529 defense allocation against natural enemies. Evolution 58:1685-1616-1695

530 Gershenzon J (1984) Changes in the levels of plant secondary metabolites under water and 531 nutrient stress. Recent Adv Phytochem 18:273-320

532 Giamoustaris A, Mithen R (1995) The effect of modifying the glucosinolate content of leaves of $533 \quad$ oilseed rape (Brassica napus ssp. oleifera) on its interaction with specialist and generalist pests. Ann Appl Biol 126:347-363

535 Herms DA, Mattson WJ (1992) The dilemma of plants: to grow or defend. Q Rev Biol 67:283$536 \quad 335$

537 Hirata K, Asada M, Yatani E, et al (1993) Effects of near-ultraviolet light on alkaloid production 538 in Catharanthus roseus plants. Planta Med 59:46-50 
539 Iwasa Y, Kubo T (1997) Optimal size of storage for recovery after unpredictable disturbances.

$540 \quad$ Evol Ecol 11:41-65

541 Katjiua MLJ, Ward D (2006) Resistance and tolerance of Terminalia sericea trees to simulated 542 herbivore damage under different soil nutrient and moisture conditions. J Chem Ecol $543 \quad 32: 1431-1443$

544 Leimu R, Koricheva J (2006) A meta-analysis of tradeoffs between plant tolerance and resistance 545 to herbivores: combining the evidence from ecological and agricultural studies. Oikos $546 \quad 112: 1-9$

547 Manzaneda AJ, Prasad KVSK, Mitchell-Olds T (2010) Variation and fitness costs for tolerance to 548 different types of herbivore damage in Boechera stricta genotypes with contrasting 549 glucosinolate structures. New Phytol 188:464-477

550 Marak HB, Biere A, van Damme JMM (2000) Direct and correlated responses to selection on 551 iridoid glycosides in Plantago lanceolata L. J Evolution Biol 13:985-996

552 Marak HB, Biere A, van Damme JMM (2002) Two herbivore-deterrent iridoid glycosides reduce 553 the in-vitro growth of a specialist but not of a generalist pathogenic fungus of Plantago $554 \quad$ lanceolata L. Chemoecology 12:185-192

555 Marak HB, Biere A, van Damme JMM (2003) Fitness costs of chemical defense in Plantago 556 lanceolata L.: effects of nutrient and competition stress. Evolution 57:2519-2530

557 Mauricio R, Rausher MD, Burdick DS (1997) Variation in the defense strategies of plants: Are $558 \quad$ resistance and tolerance mutually exclusive? Ecology 78:1301-1311

559 Muola A, Mutikainen P, Laukkanen L, et al (2010) Genetic variation in herbivore resistance and 560 tolerance: the role of plant life-history stage and type of damage. J Evol Biol 23:21855612196 
562 Nieminen M, Suomi J, van Nouhuys S, et al (2003) Effect of iridoid glycoside content on

563 oviposition host plant choice and parasitism in a specialist herbivore. J Chem Ecol 29:823-844

565 Núñez-Farfán J, Fornoni J, Valverde PL (2007) The evolution of resistance and tolerance to 566 herbivores. Annu Rev Ecol Evol Syst 38:541-566

567 Oduor AMO, Lankau RA, Strauss SY, et al (2011) Introduced Brassica nigra populations exhibit 568 greater growth and herbivore resistance but less tolerance than native populations in the $569 \quad$ native range. New Phytol 191:536-544

570 Pereyra PC, Bowers MD (1988) Iridoid glycosides as oviposition stimulants for the buckeye 571 butterfly, Junonia coenia (Nymphalidae). J Chem Ecol 14:917-928

572 Preisser EL, Gibson SE, Adler LS, et al (2007) Underground herbivory and the costs of 573 constitutive defense in tobacco. Acta Oecol 31:210-215

574 Primack RB, Antonovics J (1982) Experimental ecological genetics in Plantago. VII. $575 \quad$ Reproductive effort in populations of $P$. lanceolata L. Evolution 36:742-752

576 Restif O, Koella JC (2004) Concurrent evolution of resistance and tolerance to pathogens. Am $577 \quad$ Nat 164:E90-E102

578 Reudler Talsma JH, Biere A, Harvey JA, et al (2008) Oviposition cues for a specialist butterfly: 579 plant chemistry and size. J Chem Ecol 34:1202-1212

580 Reudler JH, Biere A, Harvey JA, et al (2011) Differential performance of a specialist and two 581 582 generalist herbivores and their parasitoids on Plantago lanceolata. J. Chem. Ecol 37:765778

583 Roitto M, Rautio P, Markkola A, et al (2009) Induced accumulation of phenolics and sawfly 584 performance in Scots pine in response to previous defoliation. Tree Physiol 29:207-216 
585 Rooke T, Bergstrom R (2007) Growth, chemical responses and herbivory after simulated leaf 586 browsing in Combretum apiculatum. Plant Ecology 189:201-212

587 Rosenthal JP, Kotanen PM (1994) Terrestrial plant tolerance to herbivory. Trends Ecol Evol $588 \quad 9: 145-148$

589 Siemens DH, Garner SH, Michell-Olds T, et al (2002) Costs of defense in the context of plant $590 \quad$ competition: Brassica rapa may grow and defend. Ecology 83:505-517

591 Schmidt S, Baldwin IT (2009). Down-regulation of systemin after herbivory is associated with 592 increased root allocation and competitive ability in Solanum nigrum. Oecologia, 159:473-

594 Stamp NE, Bowers MD (1994) Effects of cages, plant age and mechanical clipping on plantain $595 \quad$ chemistry. Oecologia 99:66-71

596 Stevens MT, Waller DM, Lindroth RL (2007) Resistance and tolerance in Populus tremuloides: genetic variation, costs, and environmental dependency. Evol Ecol 21:829-847

598 Stinchcombe JR (2002) Can tolerance traits impose selection on herbivores? Evol Ecol 16:595$599 \quad 602$

600 Stowe KA (1998) Experimental evolution of resistance in Brassica rapa: correlated response of 601 tolerance in lines selected for glucosinolate content. Evolution 52:703-712

602 Stowe KA, Marquis RJ (2011) Costs of defense: correlated reponses to divergent selection for 603 foliar glucosinolate content in Brassica rapa. Evol Ecol 25:763-775

604 Stowe KA, Marquis RJ, Hochwender CG, et al (2000) The evolutionary ecology of tolerance to 605 consumer damage. Annu Rev Ecol Syst 31:565-595

606 Strauss SY, Agrawal AA (1999) The ecology and evolution of plant tolerance to herbivory. $607 \quad$ Trends Ecol Evol 14:179-185 
608 Strauss SY, Siemens DH, Decher MB, et al (1999) Ecological costs of plant resistance to 609 herbivores in the currency of pollination. Evolution 53:1105-1113

610 Strauss SY, Rudgers JA, Lau JA, et al (2002) Direct and ecological costs of resistance to 611 herbivory. Trends Ecol Evol 17:278-285

612 Strauss SY, Watson W, Allen MT (2003) Predictors of male and female tolerance to insect 613 herbivory in Raphanus raphanistrum. Ecology 84:2074-2082

614 Suomi J, Wiedmer SK, Jussila M et al (2001) Determination of iridoid glycosides by micellar 615 electrokinetic capillary chromatography-mass spectrometry with use of the partial filing 616 technique. Electrophoresis 22:2580-2587

617 Tiffin P (2000a) Mechanisms of tolerance to herbivore damage: what do we know? Evol Ecol 618 $14: 523-536$

619 Tiffin P (2000b) Are tolerance, avoidance, and antibiosis evolutionarily and ecologically 620 equivalent responses of plants to herbivores? Am Nat 155:128-138

621 Tucker C, Avila-Sakar G (2010) Ontogenetic changes in tolerance to herbivory in Arabidopsis. $622 \quad$ Oecologia 164:1005-1015

623 Tuomi J, Niemela P, Chapin FS, et al (1988) Defensive responses of trees in relation to their 624 carbon/nutrient balance. In: Mattson WJ, Levieux J,Bernard-Dagan C (eds) Mechanisms 625 of woody plant defenses against insects: search for pattern. Springer-Verslag, New York, $626 \quad$ pp $57-72$

627 van Dam NM, Baldwin IT (2001) Competition mediates costs of jasmonate-induced defences, 628 nitrogen acquisition and transgenerational plasticity in Nicotiana attenuata. Funct Ecol 629 $15: 406-415$

630 van der Meijden E (1996) Plant defence, an evolutionary dilemma: contrasting effects of 631 (specialist and generalist) herbivores and natural enemies. Entomol Exp Appl 80:307-310 
632 van der Meijden E, Wijn M, Verkaar HJ (1988) Defense and regrowth, alternative plant strategies

633 in the struggle against herbivores. Oikos 51:355-363

634 Verges A, Perez M, Alcoverro T, et al (2008) Compensation and resistance to herbivory in 635 seagrasses: induced responses to simulated consumption by fish. Oecologia 155:751-760

636 Wurst S, van Dam NM, Monroy F, et al (2008) Intraspecific variation in plant defense alters 637 effects of root herbivores on leaf chemistry and aboveground herbivore damage. J Chem $638 \quad$ Ecol 34:1360-1367

639 Zangerl AR, Berenbaum MR (1997) Cost of chemically defending seeds: furanocoumarins and $640 \quad$ Pastinaca sativa. Am Nat 150:491-504

641 Zavala JA, Baldwin IT (2006) Jasmonic acid signalling and herbivore resistance traits constrain 642 regrowth after herbivore attack in Nicotiana attenuata. Plant Cell Environ 29:1751-1760 


\section{Figure legends}

646 Figure 1. Leaf concentrations (\% of dry weight) of total iridoid glycosides (IG) (a), aucubin (b),

647 catalpol (c) and catalpol-to-total-IG ratio (d) of Plantago lanceolata lines selected for low (white

648 bars) and high (black bars) leaf iridoid glycoside concentrations. Plants were grown under

649 nutrient poor or rich conditions and leaves were harvested at an age of eight weeks $(\mathrm{T}=8$;

650 treatment $\mathrm{R} 8$ ), thirteen weeks $(\mathrm{T}=13$, treatment $\mathrm{U13})$, or after regrowth from $\mathrm{T}=8$ until $\mathrm{T}=13$

651 following defoliation ( $\mathrm{R}$; treatment R13). Non-shared letters indicate significant differences 652 among bars (lines or time points) within nutrient treatments (LSD post-hoc tests, $\mathrm{P}<0.05$ ). Values 653 are back-transformed means \pm 1 s.e.m.

655 Figure 2. Total dry weight (a), ratio of root-to-total-biomass (b), total root dry weight (c), 656 number of rosettes (d), number of leaves (e), leaf area of the longest leaf (f), number of 657 inflorescences (g), dry weight of inflorescences (h), and total vegetative shoot dry weight (i) of 658 Plantago lanceolata lines selected for low (white bars) and high (black bars) leaf iridoid 659 glycoside concentrations. Plants were grown under nutrient poor or rich conditions and harvested 660 at an age of eight weeks ( $\mathrm{T}=8$; treatment U8), thirteen weeks $(\mathrm{T}=13$; treatment $\mathrm{U} 13)$ or after 661 regrowth from $\mathrm{T}=8$ until $\mathrm{T}=13$ following defoliation ( $\mathrm{R}$; treatment $\mathrm{R} 13)$. Asterisks indicate 662 significant differences between lines for each treatment combination (line effect tested over cross 663 within line). $+\mathrm{P}<0.10 ; * \mathrm{P}<0.05 ; * * \mathrm{P}<0.01 ; * * * \mathrm{P}<0.001$. Values are back-transformed means \pm 6641 s.e.m.

665

666 Figure 3. Mean weight of $P$. lanceolata shoots at $\mathrm{T}=13$ that had regrown following defoliation at $667 \mathrm{~T}=8$, as a function of their mean estimated root dry weight at the time of defoliation $(\mathrm{T}=8)$. 
668 Values are mean values for progeny of eight crosses derived from a low-IG line (open symbols)

669 and eight crosses from a high-IG line (closed symbols) grown under nutrient-poor (circles) or 670 rich (squares) conditions. Note the log-scale of both axes.

671

672 Figure 4. Mean dry weight of roots at $\mathrm{T}=13$, five weeks after defoliation, as a function of the 673 mean iridoid glycoside (IG) concentration in the leaves of the same $P$. lanceolata plants at $\mathrm{T}=8$, 674 the time of defoliation. Values are mean values for progeny of eight crosses derived from a low675 IG line (open symbols) and eight crosses from a high-IG line (closed symbols) grown under 676 nutrient-poor conditions. Note the log-scale of both axes.

677 
Figure 1

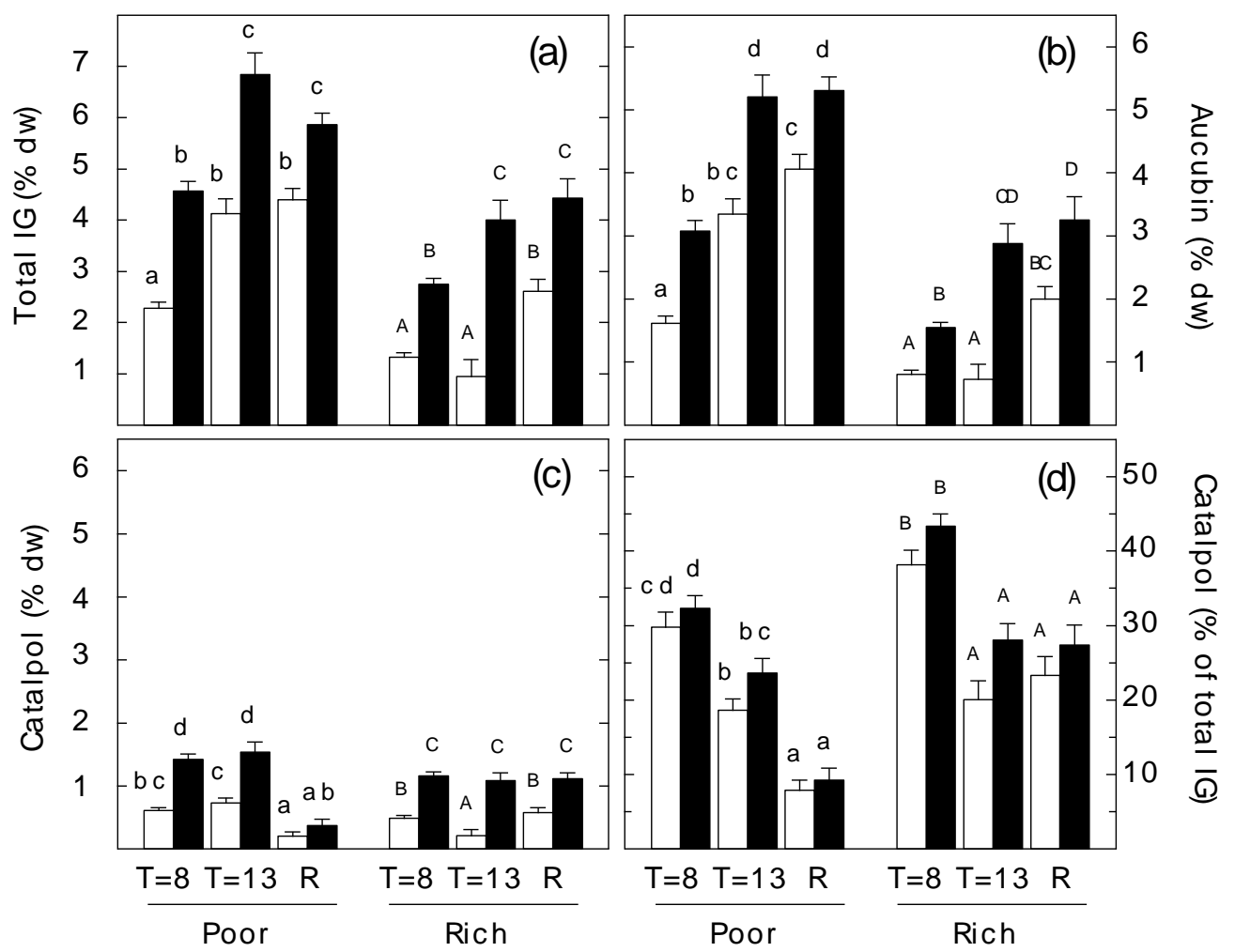




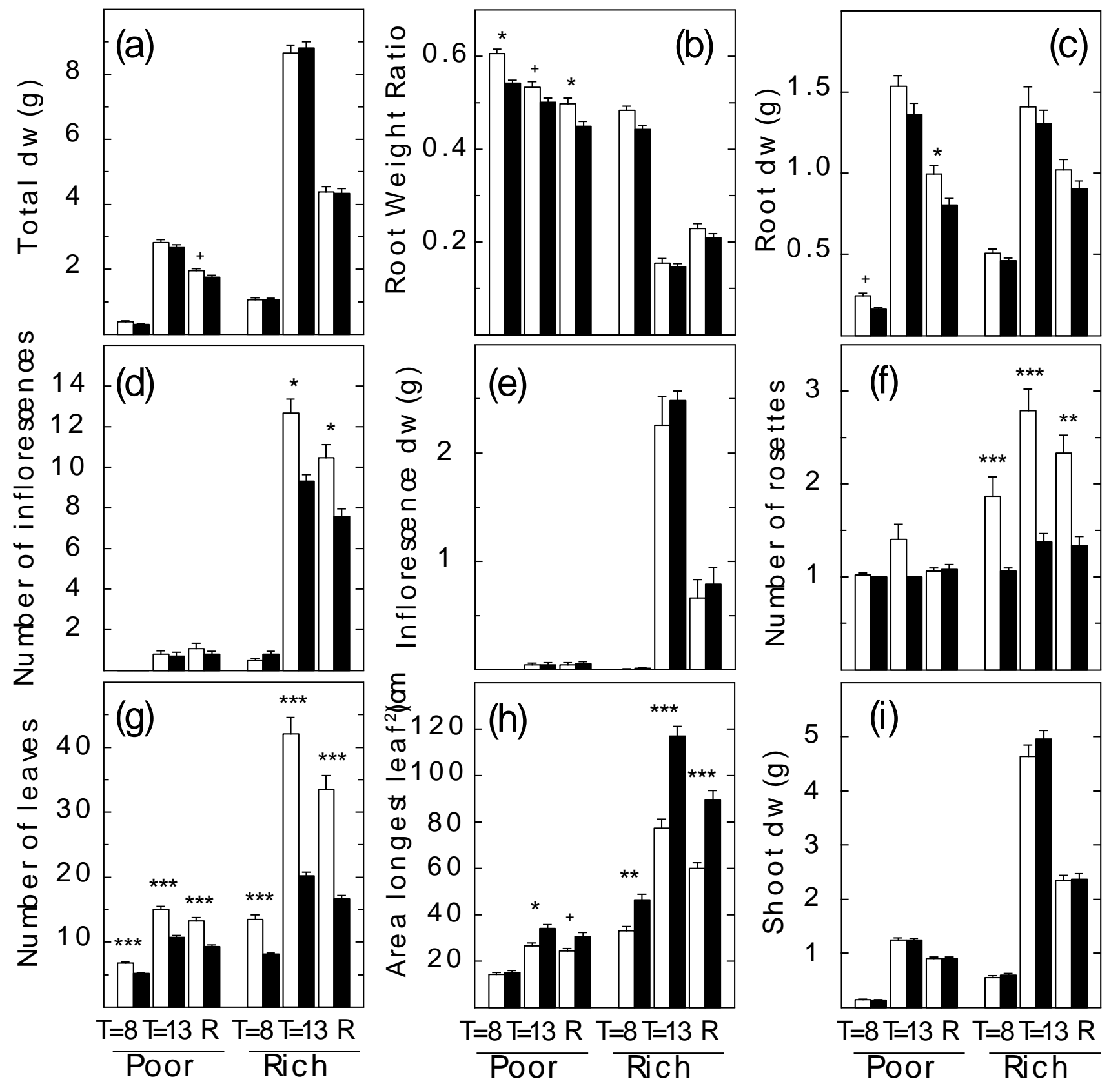


683 Figure 3

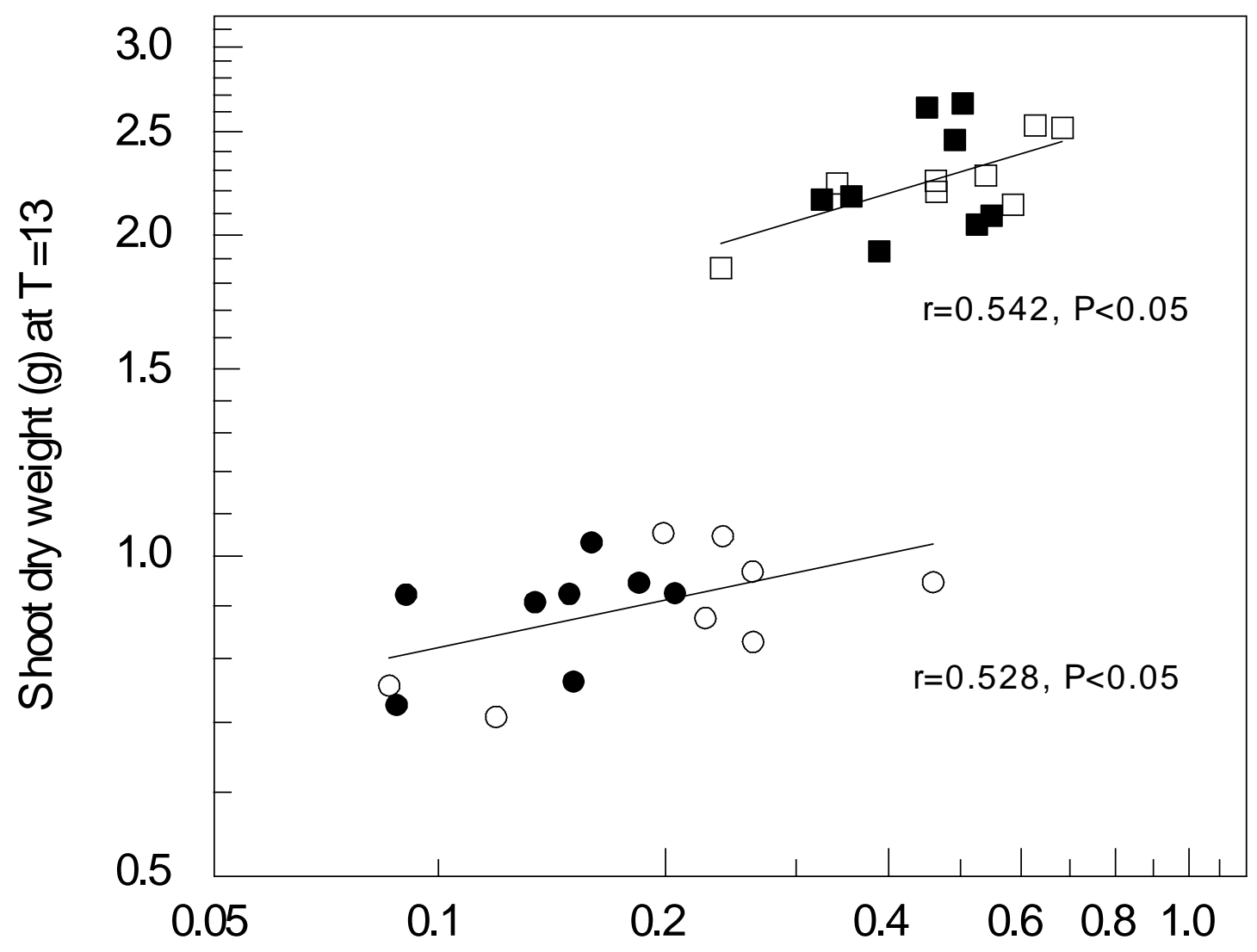

Estimated root dry weight (g) at $\mathrm{T}=8$ 
685 Figure 4

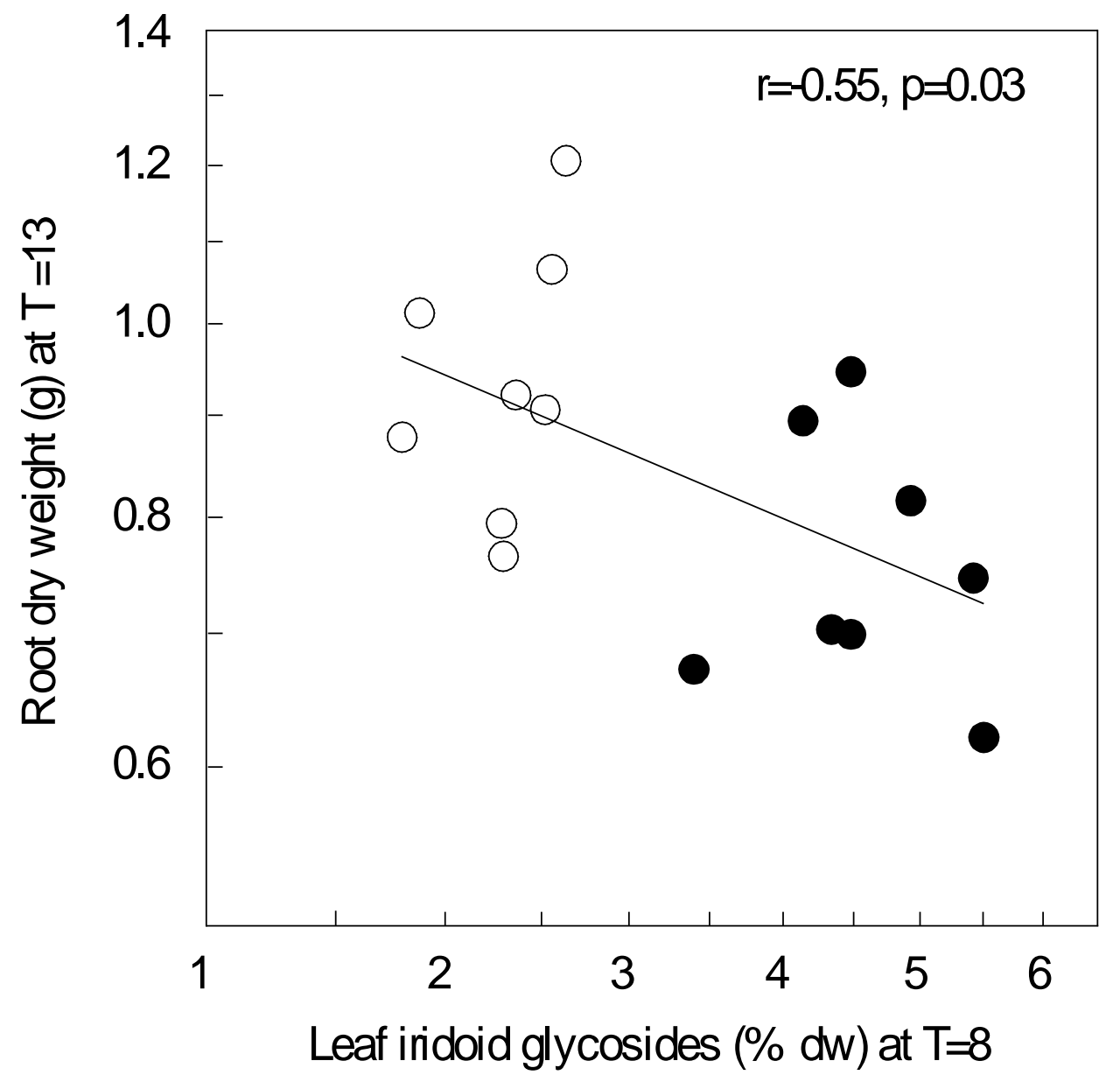

686 